\title{
LINC00669 insulates the JAK/STAT suppressor SOCS1 to promote nasopharyngeal cancer cell proliferation and invasion
}

Xiang Qing ${ }^{1}$, Guo-lin Tan ${ }^{1}$, Huo-wang Liư ${ }^{1}$, Wei Li ${ }^{1}$, Jin-gang Ai ${ }^{1}$, Shan-shan Xiong ${ }^{1}$, Meng-qing Yang ${ }^{2}$ and Tian-sheng Wang ${ }^{1 *}$

\begin{abstract}
Nasopharyngeal carcinoma (NPC) is an epithelial cancer emerging from the lining of nasopharyngeal mucosa, with extremely frequent occurrence in east and southeast Asia. For the purpose of exploring roles of the dysregulated long non-coding RNA (IncRNA) in NPC, we identified a novel IncRNA LINC00669 with an apparent negative correlation to the overall survival from human NPC mRNA expression profiling databases. We further performed RNA pulldown coupled with mass spectrum to find out its target protein, and applied a series of in vitro and in vivo loss-and-gain-of function assays to investigate its oncogenic roles in NPC tumor development and progression. Our results demonstrated that LINC00669 competitively binds to the key JAK/STAT signaling pathway suppressor SOCS1, and insulates it from imposing ubiquitination modification on the pathway component of STAT1, which leads to its abnormal stabilization and activation. The activated STAT1 is then transferred into the nucleus and initiates the transcription of genes related to proliferation and invasion. In summary, our study reveals that the cytoplasmic resident IncRNA LINC00669 confers malignant properties on NPC cancer cells by facilitating a persistent activation of the JAK/STAT signaling pathway. Findings in the current study shed lights on prospects for treating NPC using strategies targeting the novel regulator of the JAK/STAT signaling.
\end{abstract}

Keywords: Nasopharyngeal carcinoma, Long non-coding RNA, LINC00669, JAK/STAT, SOCS1, STAT1

\section{Introduction}

Nasopharyngeal carcinoma (NPC) is one of the most frequent malignant tumors with extremely high occurrence in Southern China, Northern Africa and parts of the Mediterranean basin [1]. Most NPC is moderately sensitive to radiation therapy, which has been the preferred treatment thus far [2]. However, NPC is featured as a type of poor or undifferentiated carcinoma with only

\footnotetext{
* Correspondence: tianshengwang@csu.edu.cn

'Department of Otolaryngology Head and Neck Surgery, The Third Xiangya Hospital, Central South University, Changsha 410013, China

Full list of author information is available at the end of the article
}

$41-63 \%$ overall survival rate in patients at the advanced stage $[3,4]$. Therefore, deeper insights into the molecular mechanisms that underlie NPC development and progression warrant the better therapeutic strategies targeting the disease.

Long non-coding RNA (lncRNA) is a class of longer than 200 nucleotides RNA transcripts [5]. Emerging studies have shown that lncRNAs participate in NPC development and progression. For example, maternally expressed gene 3 (MEG3) was identified as a tumor suppressor lncRNA that is downregulated in NPC due to losses of DNA copy numbers and aberrant promoter

C C The Author(s). 2020 Open Access This article is licensed under a Creative Commons Attribution 4.0 International License, which permits use, sharing, adaptation, distribution and reproduction in any medium or format, as long as you give appropriate credit to the original author(s) and the source, provide a link to the Creative Commons licence, and indicate if changes were made. The images or other third party material in this article are included in the article's Creative Commons licence, unless indicated otherwise in a credit line to the material. If material is not included in the article's Creative Commons licence and your intended use is not permitted by statutory regulation or exceeds the permitted use, you will need to obtain permission directly from the copyright holder. To view a copy of this licence, visit http://creativecommons.org/licenses/by/4.0/ The Creative Commons Public Domain Dedication waiver (http://creativecommons.org/publicdomain/zero/1.0/) applies to the data made available in this article, unless otherwise stated in a credit line to the data. 
methylation [6]. On the contrary, LncRNA HOX transcript antisense intergenic RNA (HOTAIR) acts as an oncogene, whose high abundance in NPC cells and the patient tumor samples correlates with a poor prognosis [7, 8]. With the advance of microarray and high-throughput RNA sequencing, a large number of lncRNAs have been identified in NPC tissues and cell lines [9]. However, the roles of these dysregulated lncRNAs in the pathogenesis of NPC remain poorly understood.

The Janus kinase (JAK)-signal transducer of activators of transcription (STAT) signaling pathway is involved in diverse biological processes such as cell proliferation, differentiation, apoptosis, and immune regulation [10]. It mainly consists of three components, namely tyrosine-kinase-related receptor, tyrosine kinase JAK and transcription factor STAT. The binding of cytokines to their receptors activates JAKs and promote STAT nuclear translocation to initiate the corresponding gene transcription, including the expression of SOCS which feeds back negatively to shut down the signaling pathway [11]. It was reported that the abnormal JAK/STAT signaling with persistent activation of STAT1, 3 and 5 has a cancer-promoting role in the progression of Epstein-Barr virus (EBV)related NPC [12]. Therefore, suppression of the aberrantly activated JAK/STAT signaling pathway could be promising strategy for NPC therapy.

In current study, we demonstrated an abnormal accumulation of lncRNA LINC00669 in the cytoplasm of NPC cells, where it binds to the key JAK/STAT signaling pathway suppressor SOCS1 and blocks its ubiquitin ligase activity toward the transcription factor STAT1. The stabilized STAT1 is further activated and translocated into the nucleus to initiate expression of genes associated with proliferation and invasion. These results shed light on a clinical implication of LINC00669 as a diagnostic and prognostic marker as well as a therapeutic target of NPC.

\section{Materials and methods}

\section{Ethical statement}

All animal experiments were conducted in accordance with the guidelines of Animal Experimentation Ethics Committee of the Third Xiangya Hospital of Central South University. Clinical NPC tumor and para-tumor samples were collected from 16 patients with informed consents being signed by all of the patients.

\section{Cell lines and treatment}

All the NPC cell lines and normal human nasopharyngeal epithelial cell line NP69 were purchased from the Chinese Academy of Sciences Cell Bank (Shanghai, China). NPC cells were cultured in Dulbecco's modified Eagle's medium (Gibco, Thermo Fisher Scientific, Inc., Waltham, MA, USA) containing 10\% fetal bovine serum
(FBS) (Sigma-Aldrich, St. Louis, MO, USA) and 1\% antibiotics $(100 \mathrm{U} / \mathrm{ml}$ penicillin and $100 \mathrm{mg} / \mathrm{ml}$ streptomycin sulfates), while NP69 cells were maintained in the RPMI1640 medium containing 10\% FBS and 1\% penicillin/streptomycin. Cycloheximide $(20 \mathrm{mg} / \mathrm{ml}$, Millipore Sigma, \#C7698) and MG132 (5 $\mu$ M, Sigma-Aldrich, \#1211877-36-9) were used for studying ubiquitinproteasome-mediated protein degradation.

\section{Nucleic acid extraction and mRNA expression quantification}

Total RNA of NPC tissues and cells was extracted using TRIzol reagent (Invitrogen; Thermo Fisher Scientific, Inc.), followed by reverse transcription using RevertAidTM H Minus First Strand cDNA Synthesis Kit (Fermentas). The relative mRNA contents were quantified by quantitative PCR (qPCR) using SYBR Green PCR Master Mix (ABI 4309155) in the ABI7900 RealtimePCR machine. Primers used for qPCR analysis were included in Table 1.

Table 1 Primer list

\begin{tabular}{|c|c|}
\hline \multicolumn{2}{|l|}{ Primers for $\mathrm{qPCR}$} \\
\hline Genes & Primer sequences $\left(5^{\prime}--3^{\prime}\right)$ \\
\hline Primers U1 -F & GGGAGATACCATGATCACGAAGGT \\
\hline Primers U1 -R & CCACAAATTATGCAGTCGAGTTTCCC \\
\hline JAK2-F & ATCCACCCAACCATGTCTTCC \\
\hline JAK2-R & ATTCCATGCCGATAGGCTCTG \\
\hline JAK3-F & CCTGATCGTGGTCCAGAGAG \\
\hline JAK3-R & GCAGGGATCTTGTGAAATGTCAT \\
\hline STAT1-F & CAGCTTGACTCAAAATTCCTGGA \\
\hline STAT1-R & TGAAGATTACGCTTGCTITTCCT \\
\hline STAT3-F & ATCACGCCTTCTACAGACTGC \\
\hline STAT3-R & CATCCTGGAGATTCTCTACCACT \\
\hline SOCS1-F & TाTCGCCCTTAGCGTGAAGA \\
\hline SOCS1-R & GAGGCAGTCGAAGCTCTCG \\
\hline LINC00669-F & CAGTGAGATGCAGAGCTTGG \\
\hline LINC00669-R & TGTCCTTGAGGCTGTCTGTG \\
\hline$\beta$-actin $-F$ & CATGTACGTTGCTATCCAGGC \\
\hline$\beta$-actin - R & CTCCTTAATGTCACGCACGAT \\
\hline \multicolumn{2}{|c|}{ Oligonucleotide sequence for RNA pulldown } \\
\hline $\begin{array}{l}\text { LINC00669- } \\
\text { sense-F }\end{array}$ & $\begin{array}{l}\text { TAATACGACTCACTATAGGGAGACTGTGTGGAA } \\
\text { CTTGGGATTCGAACGG }\end{array}$ \\
\hline $\begin{array}{l}\text { LINC00669- } \\
\text { sense-R }\end{array}$ & CAATTITGATTGGCTTTATTTGATGTG \\
\hline $\begin{array}{l}\text { LINC00669- } \\
\text { antisense-F }\end{array}$ & CTGTGTGGAACTTGGGATTCGAACGG \\
\hline $\begin{array}{l}\text { LINC00669- } \\
\text { antisense-R }\end{array}$ & $\begin{array}{l}\text { TAATACGACTCACTATAGGGAGACAATTITGAT } \\
\text { TGGCTITATTTGATGTG }\end{array}$ \\
\hline
\end{tabular}




\section{Gene cloning, knockdown and overexpression}

The truncated LINC00669 plasmids were constructed using Phusion Site-Directed Mutagenesis Kit (Thermo Fisher Scientific, Inc., Waltham, MA, USA) by following the manual instruction. In vitro loss-of-function studies were performed by pre-designed siRNA from Millipore Sigma using Lipofectamine 2000 (Invitrogen; Thermo Fisher Scientific, Inc.). For in vivo xenograft experiment, lentiviral vectors expressing shLINC00669, SOCS1, shSOCS1 and the empty lentiviral vector were purchased from GeneChem (Shanghai, China for the stable infection of CNE-2 cells upon puromycin $(2 \mu \mathrm{g} / \mathrm{ml})$ selection.

\section{Western blotting}

Total proteins from NPC tissues and cells were extracted using RIPA buffer (1\% NP-40, 0.1\% SDS, $50 \mathrm{mM} \mathrm{DTT)}$ supplemented with protease inhibitor cocktail containing $2 \mu \mathrm{g} / \mathrm{ml}$ Aprotinin, $2 \mu \mathrm{g} / \mathrm{ml}$ Leupeptin and $1 \mathrm{mM}$ PMSF. An equal amount of total protein from each sample was separated by $8 \sim 15 \%$ SDS-PAGE gel and electroblotted onto a polyvinylidene difluoride membrane. Immunoblotting was conducted using antibodies listed in Table 2.

\section{Co-immunoprecipitation (Co-IP)}

Total proteins from NPC cells cultured in 10-cm culture dishes were used for Co-IP assay. Briefly, primary antibodies against SOCS1 or STAT1 were added in each cell lysate and incubated overnight at $4{ }^{\circ} \mathrm{C}$ with rotation. The normal human IgG protein was used as a negative control. Protein A/G agarose beads (Beyotime Biotechnology, \#P1012) were then added for affinity binding of primary antibody by a $2 \mathrm{~h}$-incubation at $4{ }^{\circ} \mathrm{C}$ with gentle rotation. The unbound antibodies were washed off through the sequential wash with PBS and cell lysis buffer. The agarose beads were resuspended in $20 \mu \mathrm{l} 1 \mathrm{x}$ SDS-PAGE loading buffer, and boiled for western blot analysis of the precipitated target proteins.

\section{Cell proliferation assay}

Time-dependent NPC cell proliferation was characterized by MTT cell proliferation and cytotoxicity detection kit (KeyGEN Biotech, \#KGA312) by following the manual instruction.

\section{Wound-healing assay}

NPC cell migration was characterized by wound-healing assay. Briefly, a confluent monolayer of NPC cells in 24well plate was scratched using a sterile $100 \mu \mathrm{l}$ pipette tip. Cells were then allowed to expand in FBS-reduced growth medium (1\%) for another $48 \mathrm{~h}$. The migration was assessed using the scratch ratio by dividing the interval at the starting point $(0 \mathrm{~h})$ with the one at the ending point $(48 \mathrm{~h})$.

\section{Transwell assay}

NPC cells were seeded into the Matrigel (BD Biosciences, San Jose, CA)-coated upper chamber of $8.0 \mu \mathrm{m}$ pore size Transwell apparatus (Corning, NY, USA) with serum-free medium. Growth medium supplemented with 10\% FBS was added to the lower chamber as a chemoattractant. The cells were allowed to invade for $48 \mathrm{~h}$ at $37{ }^{\circ} \mathrm{C}$ under $5 \% \mathrm{CO}_{2}$. Cells invaded to the lower surface of filter were then fixed in $70 \%$ ethanol for 30 min followed with staining by $0.1 \%$ crystal violet for 10 min at room temperature.

\section{Fluorescence in situ hybridization (FISH)}

Cellular LINC00669 localization was characterized using the fluorescence in situ hybridization kit from Ribo Bio (Guangzhou, China) according to the manufacturer's instruction.

\section{Cell apoptosis}

NPC cell apoptosis were determined by flow cytometry using Annexin V-PE/7-AAD Apoptosis Kit (Abnova, \#KA3809) according to the manual instruction.

Table 2 Antibody list

\begin{tabular}{|c|c|c|c|c|c|}
\hline Primary antibodies & $\mathrm{MW}(\mathrm{kDa})$ & Dilution & Company / Catalog & Secondary antibodies & Dilution \\
\hline SOCS1 & $\approx 38$ & $1: 500$ & Santa Cruz, sc-518,028 & Goat Anti Rabbit IgG/HRP & $1: 4000$ \\
\hline JAK2 & $\approx 120$ & $1: 500$ & omnimabs,OM206683 & Goat Anti Rabbit IgG/HRP & $1: 4000$ \\
\hline JAK3 & $\approx 125$ & $1: 1000$ & omnimabs,OM260121 & Goat Anti Mouse lgG/HRP & $1: 4000$ \\
\hline STAT1 & $\approx 87$ & $1: 1000$ & Abcam,ab234400 & Goat Anti Rabbit lgG/HRP & $1: 4000$ \\
\hline STAT3 & $\approx 88$ & $1: 2000$ & Abcam,ab119352 & Goat Anti Mouse lgG/HRP & $1: 4000$ \\
\hline p-STAT1(Y701) & $\approx 87$ & $1: 1000$ & Abcam,ab29045 & Goat Anti Mouse lgG/HRP & $1: 4000$ \\
\hline UB & $\approx 8.4$ & $1: 200$ & Ptgen,10,201-2-AP & Goat Anti Rabbit lgG/HRP & $1: 4000$ \\
\hline HIS & & $1: 500$ & Abcam,ab18184 & Goat Anti Mouse lgG/HRP & $1: 4000$ \\
\hline GFP & & $1: 1000$ & Abcam,ab290 & Goat Anti Rabbit IgG/HRP & $1: 4000$ \\
\hline FLAG & & $1: 1000$ & Abcam,ab205606 & Goat Anti Rabbit IgG/HRP & $1: 4000$ \\
\hline$\beta$-actin & 42 & $1: 2000$ & Ptgcn, 66,009-1-lg & Goat Anti Mouse lgG/HRP & $1: 4000$ \\
\hline
\end{tabular}


Immunohistochemistry (IHC)

Tissues for IHC were fixed in $10 \%$ buffered formalin for $24 \mathrm{~h}$ and embedded in paraffin. The deparaffinized and rehydrated sections were blocked for endogenous peroxidase by incubation in 3\% hydrogen peroxide followed with antigen retrieval in the boiling citrate buffer (10 $\mathrm{mM}, \mathrm{pH}$ 6.0) for $10 \mathrm{~min}$. The sections were then blocked with normal goat serum (1:10) and subject to incubation with anti-Ki67 monoclonal antibody (1:100, Dako, Glostrup, Denmark) or anti-Caspase 3 antibody (1:100, Abcam, \#ab32351) overnight at $4{ }^{\circ} \mathrm{C}$. Thereafter, the PBS cleaned sides were incubated with the biotinylated secondary antibody at $37^{\circ} \mathrm{C}$ for $30 \mathrm{~min}$, and subsequently incubated with a 1:200 streptavidin-biotin-peroxidase complex (Sigma, St. Louis). Reactive products were visualized with 3,3'-diaminobenzidene (DAB) as the chromogen, and nuclei were counter-stained with hematoxylin.

\section{Immunofluorescence}

NPC cells were fixed with $4 \%$ paraformaldehyde and permeabilized by $0.2 \%$ Triton X-100. After $1 \mathrm{~h}$ blocking with $1 \%$ bovine serum albumin at room temperature, the cells were incubated with anti-STAT1 (1:100) antibody overnight at $4{ }^{\circ} \mathrm{C}$. Next day, the cells were washed off the unbound primary antibody and stained with donkey anti-rabbit IgG Alexa Fluor 488 secondary antibody (ThermoFisher, \#A32790) for $1 \mathrm{~h}$ at room temperature.

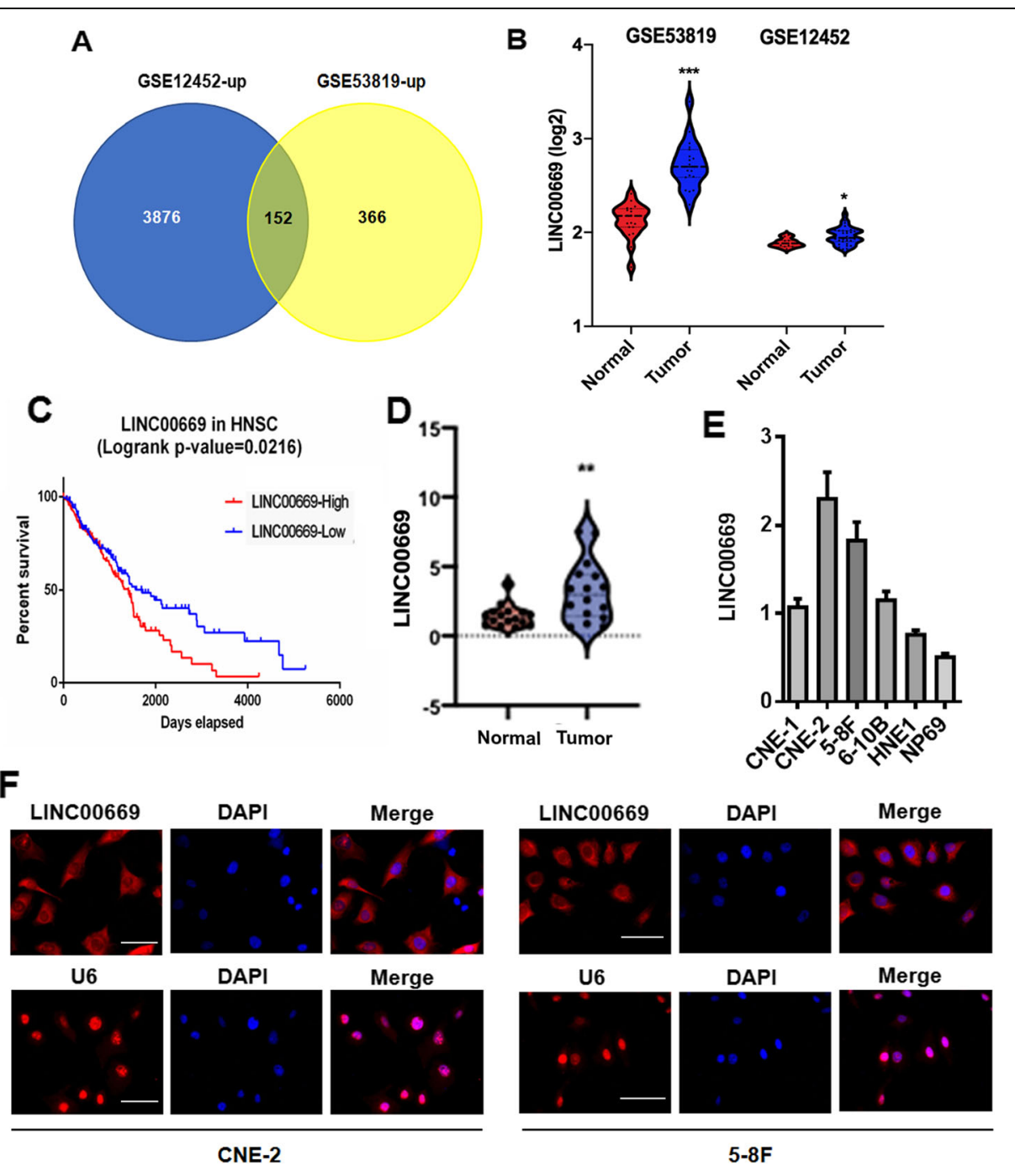

Fig. 1 Aberrant expression of LINC00669 in NPC tumors and cells. a, Venn diagram showing 152 common IncRNA signatures that are upregulated in NPC mRNA expression profiling databases of GSE12452 [14] and GSE53819 [15]. b, Microarray data showing upregulation of LINC00669 in NPC tumors. c, Kaplan-Meier analysis showing a negative correlation of the overall survival rate of NPC patients with LINC00669 level. d, qPCR analysis showing an upregulation of LINC00669 in the clinical NPC tumor samples. ${ }^{* *} p<0.01$. e, qPCR analysis showing a general upregulation of LINC00669 in different NPC cell lines. f, FISH analysis showing cytoplasmic localization of LINC00669 in NPC cells. DAPI was used for nuclear counterstaining. U6 was used as a positive control for nuclear localization 


\section{In vivo xenograft experiments}

Male BALB/c nude mice (8-week-old, $n=6$ mice/group) from Beijing HFK Bioscience Co. Ltd. (Beijing, China) were maintained under pathogen-free conditions. After subcutaneously injected with $10^{6}$ control or viral shRNA infected CNE-2 cells, the mice were monitored for tumor growth from 1 week after injection. Tumor size was calculated based on the formula of Volume $=a x b^{2}$ $\times 0.52$ (a, long diameter; $b$, short diameter).

\section{RNA pulldown assay}

Biotin-labeled full-length LINC00669 and antisense LINC00669 were synthesized in vitro using Biotin RNA Labeling Mix (Roche) and the Riboprobe Systems with T7 RNA polymerase (Promega). After DNase I treatment, the RNA probes were purified with RNeasy Mini Kit (QIAG EN). For each pulldown assay, $30 \mu \mathrm{g}$ of biotin-labeled RNA probes were incubated with CNE-2 cell lysates at room temperature for $4 \mathrm{~h}$ followed by adding pulling

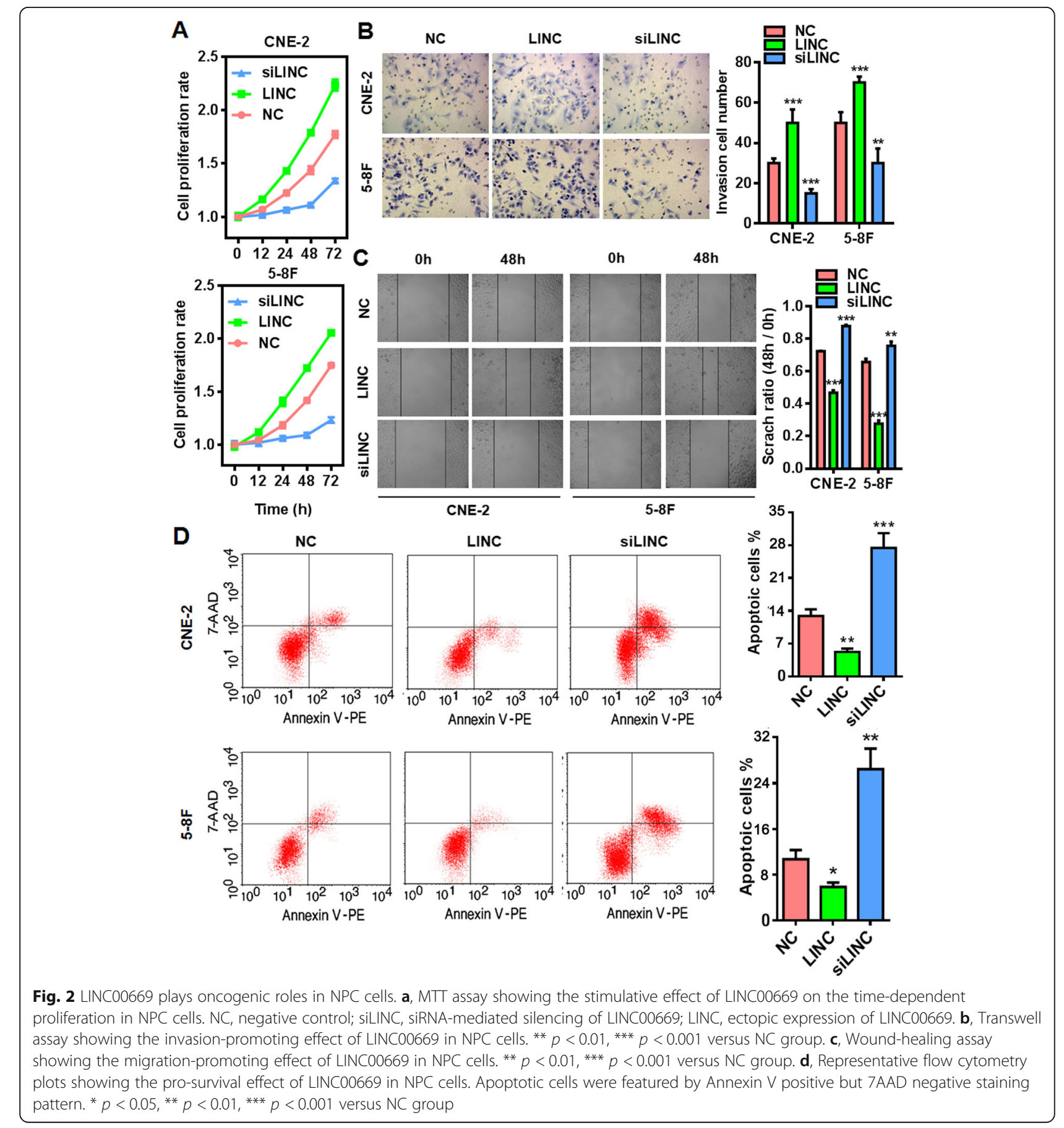


down the binding protein partner with streptavidin magnetic beads (TermoFisher, USA) at $4{ }^{\circ} \mathrm{C}$ overnight. The proteins were then separated by electrophoresis and visualized with sliver staining. The unique bands pulled down by sense LINC00669 were subject to mass spectrometry and retrieved in human proteomic library.

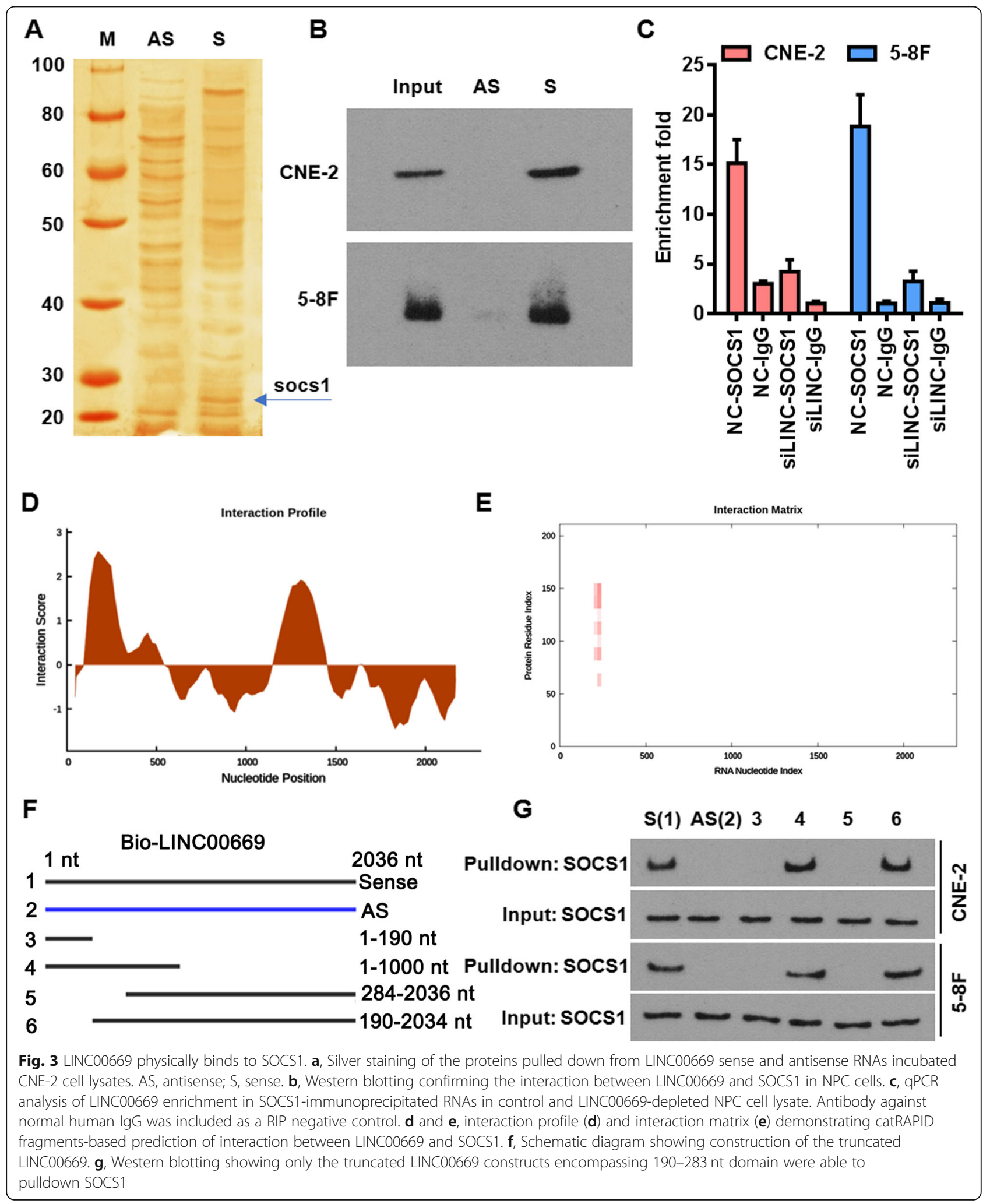


RNA immunoprecipitation (RIP)

RIP assay was conducted in wildtype and LINC00669depleted NPC cells using Magna RIP RNA-binding protein immunoprecipitation Kit (Millipore, MA) according to manufacturer's instruction. Antibodies against the normal human IgG and SNRNP70 were used as negative and positive controls for RIP, respectively. The relative enrichment of LINC00669 was normalized to the amount of the enriched U1snRNA.

\section{Bioinformatics}

The common signatures in NPC were searched by overlapping the upregulated genes $(p \leq 0.05, \log 2$ fold change $\geq 2$ ) in databases of GSE12452 and GSE53819 followed by the overall survival correlation analysis using the Signature-based statistics tool in GEPIA 2 (http://gepia2. cancer-pku.cn/\#index). In silico prediction of LINC00669-SOCS1 interaction was performed using online tools from catRAPID (http://s.tartaglialab.com/page/ catrapid_group).

\section{Statistical analysis}

Data are expressed as the mean \pm standard deviation of three independent experiments. Two-tailed Student's $t$ test was performed for detecting difference between two groups, while One-Way ANOV test was conducted for comparing two-group difference among the multiple groups using GraphPad Prism 6 software. $P<0.05$ was considered as significant.

\section{Results \\ LINC00669 is upregulated in NPC tumors and cells}

Emerging roles of lncRNA in cancer development and therapeutic opportunities have aroused wide research interest and attention [13]. To explore novel lncRNAs that play key roles in NPC, we retrieved and interrogated the expression profiles of lncRNAs in two independent NPC mRNA expression profiling databases of GSE12452 [14] and GSE53819 [15] to have identified 153 commonly upregulated signatures (Fig. 1a). None of the other lncRNAs showed significant difference in the survival curve analysis except for three classical lncRNAs of LINC00669, AFAP1-AS1 and CT75, whose upregulation are negatively correlated to the overall survival of NPC patients (Fig. 1b, c). Since LINC0069 was a novel lncRNA whose function was completely unknown, we made it the focus in our current study. Consistently, LINC00669 was confirmed by qPCR to be significantly upregulated in the patient-derived NPC tumors (Fig. 1d) and a panel of the general NPC cell lines (Fig. 1e) in comparison to their corresponding controls. Due to the highest expression of LINC00669 in CNE-2 and 5-8F among the tested cell lines, they were chosen for the subsequent functional studies. FISH assay showed that

Table 3 Domains mediating the mutual interaction between LINC00669 and SOCS1 predicted by catRAPID

\begin{tabular}{|c|c|c|c|c|c|}
\hline$\#$ & Protein region & RNA region & Interaction Propensity & Discriminative Power & Normalized Score \\
\hline 1 & $136-187$ & $190-283$ & 11.47 & 33 & 2.82 \\
\hline 2 & $126-177$ & $190-283$ & 11.36 & 33 & 2.80 \\
\hline 3 & $76-127$ & $190-283$ & 10.54 & 32 & 2.69 \\
\hline 4 & $101-152$ & $190-283$ & 10.18 & 32 & 2.64 \\
\hline 5 & $126-177$ & $185-278$ & 9.80 & 28 & 2.59 \\
\hline 6 & $51-102$ & 190-283 & 9.39 & 28 & 2.53 \\
\hline 7 & $136-187$ & $185-278$ & 9.38 & 28 & 2.53 \\
\hline 8 & $76-127$ & $185-278$ & 9.32 & 28 & 2.52 \\
\hline 9 & $101-152$ & $185-278$ & 8.48 & 26 & 2.40 \\
\hline 10 & $86-137$ & 190-283 & 8.22 & 26 & 2.37 \\
\hline 11 & $111-162$ & 190-283 & 8.06 & 26 & 2.35 \\
\hline 12 & $51-102$ & $185-278$ & 7.97 & 24 & 2.33 \\
\hline 13 & $136-187$ & $231-324$ & 7.86 & 24 & 2.32 \\
\hline 14 & $36-87$ & 190-283 & 7.59 & 24 & 2.28 \\
\hline 15 & $101-152$ & $231-324$ & 7.23 & 24 & 2.23 \\
\hline 16 & $111-162$ & $185-278$ & 7.15 & 24 & 2.22 \\
\hline 17 & $36-87$ & $185-278$ & 7.12 & 24 & 2.22 \\
\hline 18 & $26-77$ & 190-283 & 7.03 & 24 & 2.20 \\
\hline 19 & 86-137 & $185-278$ & 7.02 & 24 & 2.20 \\
\hline 20 & $26-77$ & $185-278$ & 6.17 & 22 & 2.08 \\
\hline
\end{tabular}




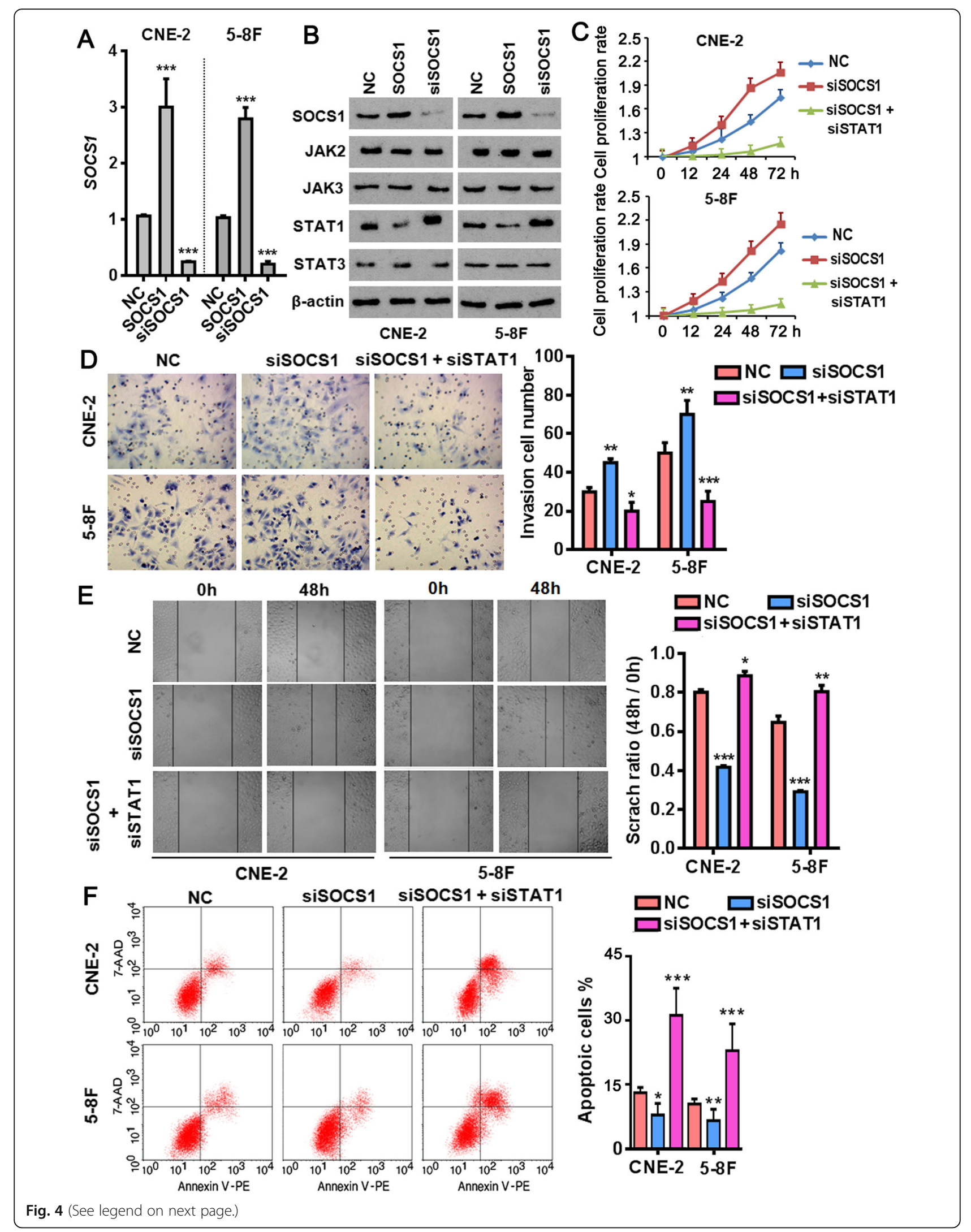




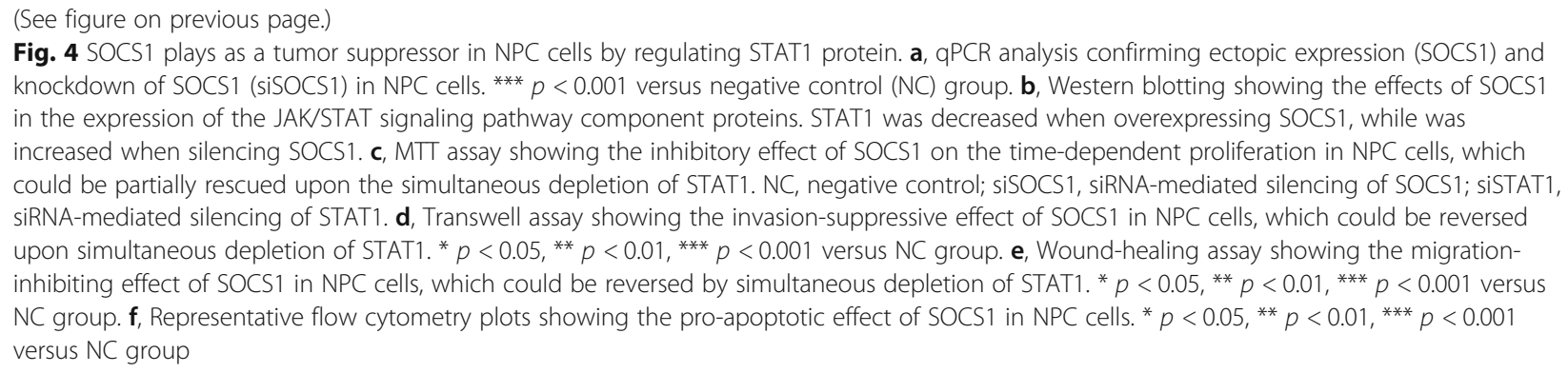

LINC00669 is dominant in the cytoplasm in both CNE-2 and 5-8F cells (Fig. 1f), indicating the potential roles involved in translational or signaling regulations.

\section{LINC00669 confers malignant properties to NPC cells}

Next, we conducted gain- and loss- of function assays to explore the functions of LINC00669 in NPC. Consistent in both CNE-2 and 5-8F cell lines, forced expression of LINC00669 dramatically promoted cell proliferation (Fig. 2a), invasion (Fig. 2b) and migration (Fig. 2c), while its depletion by small interfering RNA (siRNA) exhibited the opposite effects. Meanwhile, LINC00669 is essential for the survival of NPC cells as indicated by the strikingly induced spontaneous apoptosis upon loss of LINC00669 (Fig. 2d). Together, these data indicated that LINC00669 profoundly endows carcinogenic properties of NPC cells.

\section{LINC00669 physically interacts with SOCS1}

Inspired by the cytoplasmic localization of LINC00669 (Fig. 1e), we speculated that it might participate in the translational or signaling regulations. To identify its target proteins, we incubated CNE-2 cell lysates with a biotin-labeled LINC00669, and proceeded with electrophoresis followed by silver staining. Mass spectrum analysis of the unique protein bands detected only in the sense but not anti-sense LINC00669-incubated cell lysates by silver staining indicated SOCS1 as a potential LINC00669-targeting protein (Fig. 3a). The direct interaction between LINC00669 and SOCS1 was further confirmed by western blot on LINC00669 pulldown cell lysates using an antibody against SOCS1 (Fig. 3b). Vice versa, RNA-immunoprecipitation (RIP) assay using SOCS1 antibody followed by qPCR analysis demonstrated that SOCS1 specifically precipitated LINC00669 in both CNE-2 and 5-8F cell lysates, and the enrichment of LINC00669 was largely decreased upon siRNAmediated depletion of LINC00669 (Fig. 3c).

Next, we conducted an in-silico prediction through catRAPID [16] to map the domain in LINC00669 that mediates its interaction with SOCS1. The analytical results of both interaction profile (Fig. 3d) and interaction matrix (Fig. 3e) suggested that RNA region of 190-283 nucleotides (nt) and the protein domain ranging from 76 to 187 amino acids in SOCS1 were mostly likely to mediate the mutual binding (Table 3). Accordingly, we made a series of the truncated LINC00669 constructs flanking the site of 190-283 nt for testing their binding potentials with SOCS1 (Fig. 3f). Consistent with the predication by catRAPID, only the constructs encompassing region of 190-283 nt were able to pulldown SOCS1 (Fig. 3g). Taken together, these data indicated SOCS1 is an immediate target of LINC00669 for executing its oncogenic functions in NPC cells.

\section{SOCS1 influences various characters of NPC cells by negatively regulates the JAK/STAT signaling pathway}

The SOCS family proteins are the negative-feedback inhibitors of the JAK/STAT signaling pathway [17]. As one of the most potent family members, SOCS1 can inhibit the JAK/ STAT pathway either as a ubiquitin ligase by recruiting Cullin5 to signaling components [18] or inhibit directly the kinase activity of JAK [19]. Therefore, we determined the influences of gain- and loss- of SOCS1 (Fig. 4a) on the expression of the JAK/STAT pathway component proteins, respectively. As the western blot results displayed, STAT1 protein was dramatically decreased in the SOCS1overexpressing NPC cells, while the opposite was true when SOCS1 was silenced (Fig. 4b). Instead, the amounts of other JAK/STAT pathway component proteins including JAK2, JAK3 and STAT3 were barely affected by SOCS1. Mechanistically, SOCS1 specifically interacts with STAT1 but not other proteins in the pathway like JAK2 (Supplementary Figure 1A). The proteasome inhibitor MG132 significantly postponed degradation of both JAK2 and STAT1 in the presence of cycloheximide, indicating they are subject to a control by the ubiquitin-proteasome system. Because JAK2 did not directly interact with SOCS1 (Supplementary Figure 1A), we restricted the mechanistic investigations to STAT1 in the following studies. As expected, STAT1 was undergone a ubiquitination modification in NPC cells as evidenced by the co-immunoprecipitated ubiquitin by STAT1 (Supplementary Figure 1B). Forced expression of SOCS1 not only drastically increased total amount of the ubiquitin-modified STAT1 (Supplementary Figure 1C), but also accelerated STAT1 protein degradation (Supplementary Figure 1D) in both of the tested NPC cell lines. 


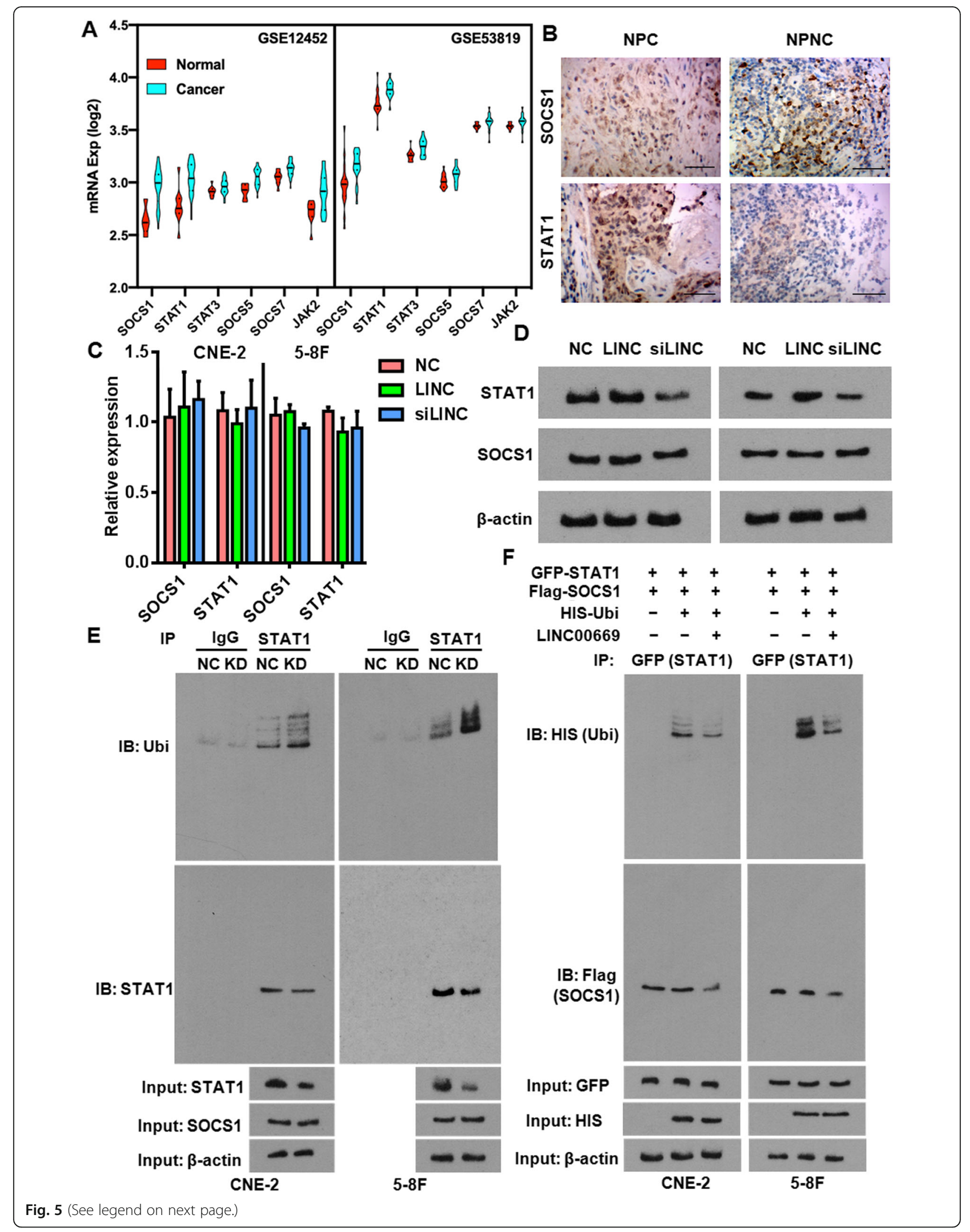


(See figure on previous page.)

Fig. 5 LINC00669 negatively regulates STAT1 ubiquitination. a, Microarray data showing upregulation of the key JAKJSTAT signaling pathway component genes in NPC tumors. b, Representative IHC results showing the aberrantly enriched STAT1 protein in NPC tumors in comparison to nasopharyngeal non cancer (NPNC) tissues. c, QPCR analysis showing neither SOCS1 nor STAT1 were subject to a changed with LINC00669 at transcription level. LINC, overexpression of LINC00669; siLINC, siRNA-mediated silencing of LINC00669. d, Western blotting showing STAT1 but not SOCS1 protein expression was regulated by LINC00668. Ectopic expression of LINC00669 increased STAT1 protein amount while depletion of LINC00668 decreased STAT1 protein abundance. e, Co-IP assay showing endogenous STAT1 ubiquitination was dramatically increased upon knockdown (KD) of LINC00669 in NPC cells. Ubi, ubiquitin. Normal lgG was used as a negative control for IP. f, Co-IP assay showing exogenous ubiquitination modification on GFP-fused STAT1 protein was dramatically diminished upon overexpressing LINC00669

The JAK/STAT signaling contributes to multiple tumor malignancies by promoting the survival, selfrenewal, and metastasis of cancer stem cells [20]. We wondered how does the SOCS1/STAT1 regulatory network affect the NPC cell phenotypes. Obviously, SOCS1-depleted NPC cells exhibited a series of the cancerous propensities including enhanced proliferation (Fig. 4c), invasion (Fig. 4d), migration (Fig. 4e) coupled with decreased spontaneous apoptosis (Fig. 4f) in comparison to the control cells. Of note, simultaneous silencing of STAT1 completely abolished all the stimulative effects in the SOCS1-depleted NPC cells. Taken together, these data indicate SOCS1 plays a role of tumor suppressor in NPC cells by directing the ubiquitin-proteasome-mediated degradation of STAT1 in the JAK/STAT signaling pathway.

\section{LINC00669 stabilizes STAT1 by holding it back from ubiquitination modification}

Aberrant activation of the JAK/STAT pathway has been found in many tumors [10]. Indeed, most of the component genes of this signaling pathway were upregulated in human NPC tumors at the transcription level (Fig. 5a). Unexpectedly, this was concurrent with upregulation of the negative feedback regulator SOCS1. We further examined the expression of SOCS1 and STAT1 proteins in NPC tumors and para-carcinoma tissues by IHC. Although SOCS1 levels were comparative between the normal and cancerous tissues, it was NPC tumors instead of para-carcinoma tissues that exhibited a strong immunostaining signal of STAT1 (Fig. 5b), indicating the interrupted Inhibition of SOCS1 on STAT1 in NPC tumors. Given the fact that SOCS1 strongly interacts

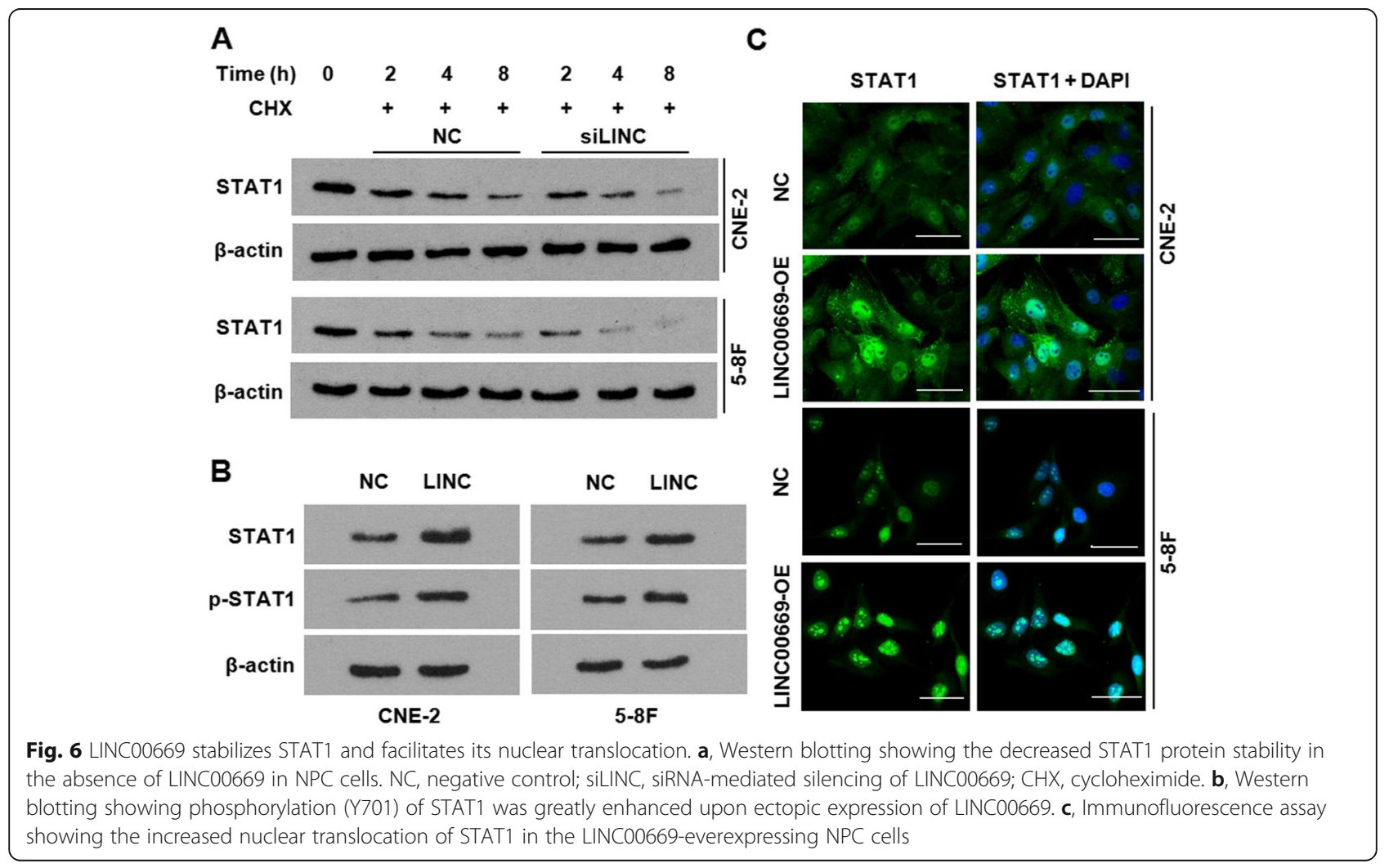




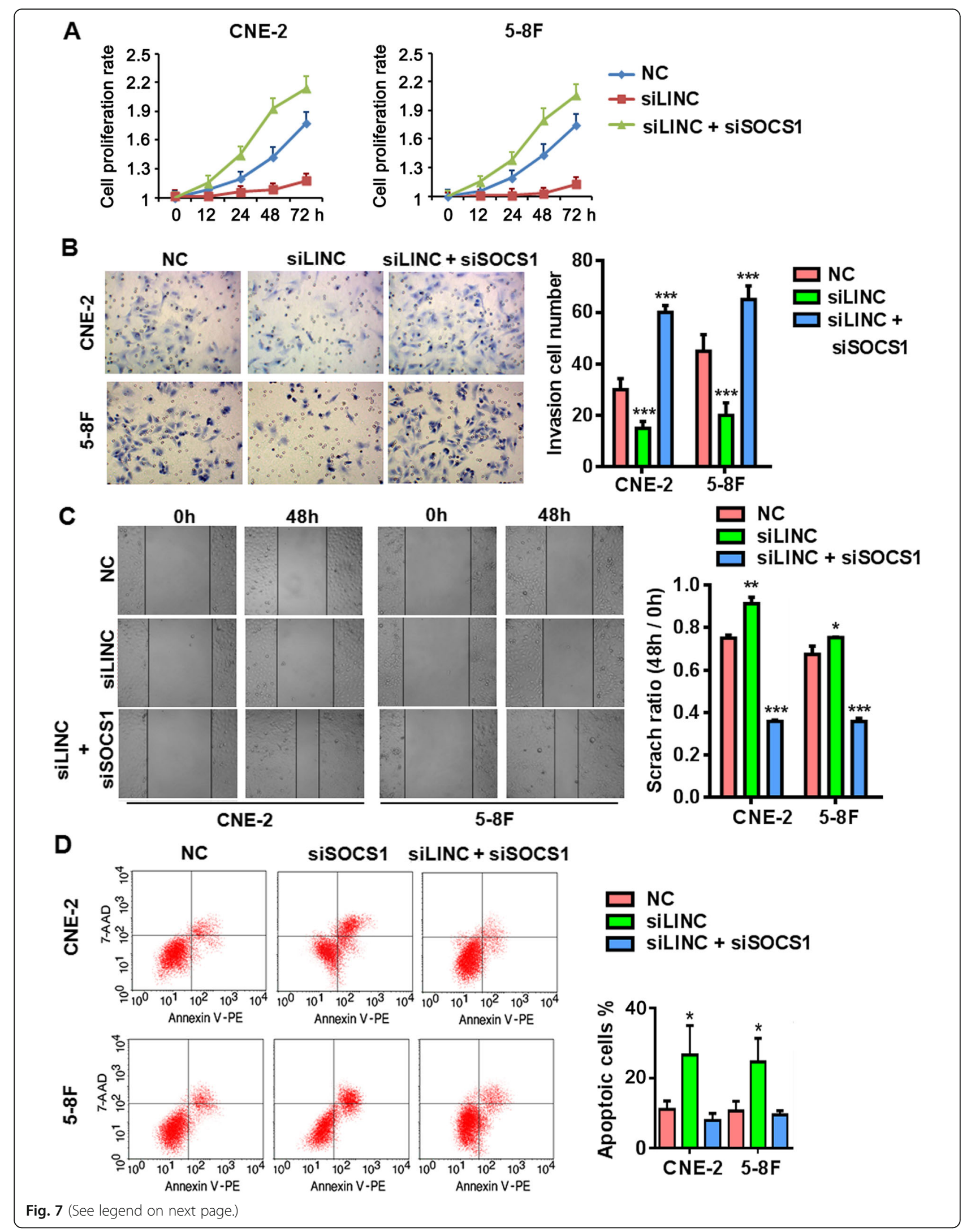




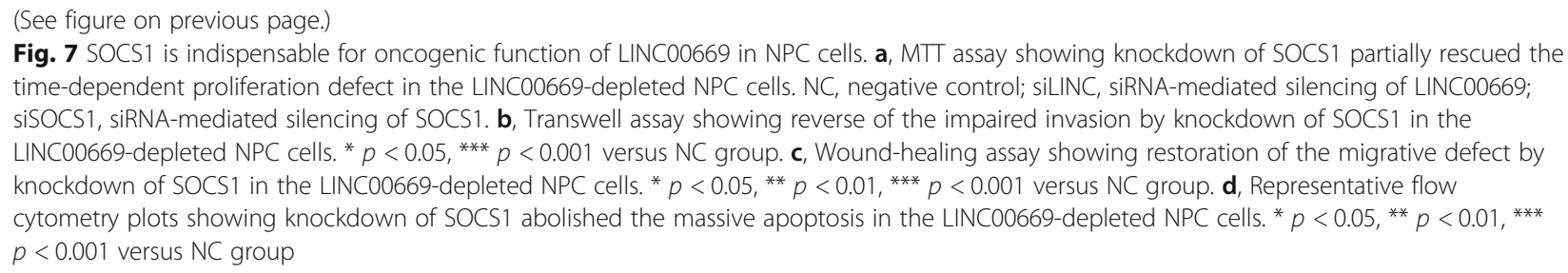

with LINC00669, which is highly expressed in NPC tumors, we investigated how changes of LINC00669 and then its interaction with SOCS1 would affect SOCS1/ STAT1 network. Obviously, transcription of SOCS1 and STAT1 did not vary with the expression of LINC00669 (Fig. 5c). Nor did SOCS1 protein change accordingly (Fig. 5d). Instead, STAT1 protein was increased when LINC00669 was overexpressed and was decreased when LINC00669 was depleted (Fig. 5d). Concomitantly, loss of LINC00669 also led to an increase in ubiquitination of STAT1 (Fig. 5e), which could be reversed upon forced expression of LINC00669 (Fig. 5f).

As SOCS1 destabilizes STAT1 through the ubiquitinproteasomal protein degradation, we postulated that changes in LINC00669 expression might also lead to the altered STAT1 protein stability in view of the apparent change in the ubiquitination modification it brought to STAT1 (Fig. 5e, f). Indeed, depletion of LINC00669 largely shortened the half-life of STAT1 as evidence by the accelerated degradation of STAT1 protein in both of the cycloheximide-treated CNE-2 and 5-8F cells (Fig. 6a). Interestingly, not only the total amount of STAT1, but also the phosphorylated STAT1 was greatly increased as a consequence of overexpressing LINC00669 (Fig. 6b), which expectedly led to a nuclear translocation of STAT1 in NPC cells (Fig. 6c).

\section{Removal of SOCS1 reverses the defective phenotypes of LINC00669-depleted NPC cells in vitro and in vivo}

Now that the establishment of LINC00669/SOCS1/STAT1regulatory cascade, we wondered whether this could be the mechanism that underlies the profound influences of LINC00669 and SOCS1 on the featured NPC cell phenotypes. As expected, silencing LINC00669 suppressed NPC cell proliferation (Fig. 7a), invasion (Fig. 7b) and migration (Fig. 7c), and induced spontaneous apoptosis (Fig. 7d). Simultaneous depletion of SOCS1 completely abolished all the detrimental effects observed in the LINC00669-silenced NPC cells.

Finally, we accessed the role of LINC00669/SOCS1/ STAT1 regulatory network in NPC carcinogenesis in vivo. CNE-2 cells with stable knockdown of LINC00669 or concomitant depletion of LINC00669 and SOCS1 were subcutaneously injected into nude mice, respectively. Comparing to the mice injected with control
CNE-2 cells, silencing LINC00669 dramatically suppressed xenografted tumor growth (Fig. 8a, b). Instead, tumor growth retardation shown in mice bearing tumors derived from LINC00669-deficient CNE-2 cells was completely reversed in the recipients injected with LINC00669 and SOCS1 double knockdown cells. In accordance, the proliferative cells in xenograft tumors derived from LINC00669 silencing CNE-2 cells were largely diminished compared to the control tumors, while tumors grown from LINC00669 and SOCS1 double knockdown CNE-2 cells were overwhelmed with massive of Ki67 positive cells (Fig. 8c). In contrast, apoptosis as indicated by Caspase 3 immunostaining appeared in an opposite pattern to that featured in proliferation (Fig. 8c).

As a whole, our study revealed a novel tumorpromoting mechanism involving LINC00669/SOCS1/ STAT1 regulatory network in NPC (Fig. 8d). Briefly, LINC00669 is aberrantly increased in the cytoplasm of NPC cells, where it binds to and prevents SOCS1 from imposing ubiquitination modification on the JAK/STAT signaling pathway component transcription factor STAT1. As a result, total and phosphorylated STAT1 are accumulated by escaping from proteasomal degradation. Phosphorylation of STAT1 facilitates its nuclear translocation and initiation of the transcriptional program for the enhanced proliferation and invasion.

\section{Discussion}

Normal cell functions are directed by the finely tuned activation and inactivation of diverse cellular signaling pathways. The JAK-STAT signaling pathway is a chain of interactions between proteins in a cell, and is involved in fundamental processes such as immunity, cell division and cell death [21]. One of the features of this pathway is characterized by the rapid activation and inactivation [22]. Activated STATs accumulate rapidly in the nucleus, and within a few hours, the inactivated STATs return to the cytoplasm and prepare for the next round of signaling. Disruption of the cellular machineries that control the JAKSTAT signaling may lead to a variety of diseases, such as skin conditions, cancers, and disorders in the immune system [23]. In this study, we revealed that 


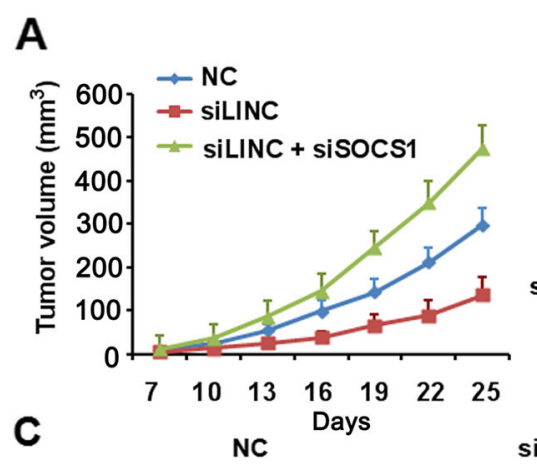

B
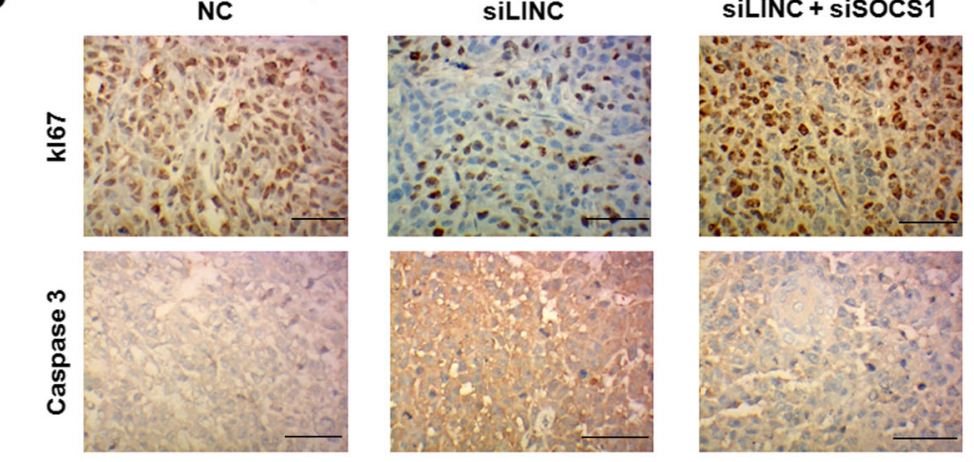

D
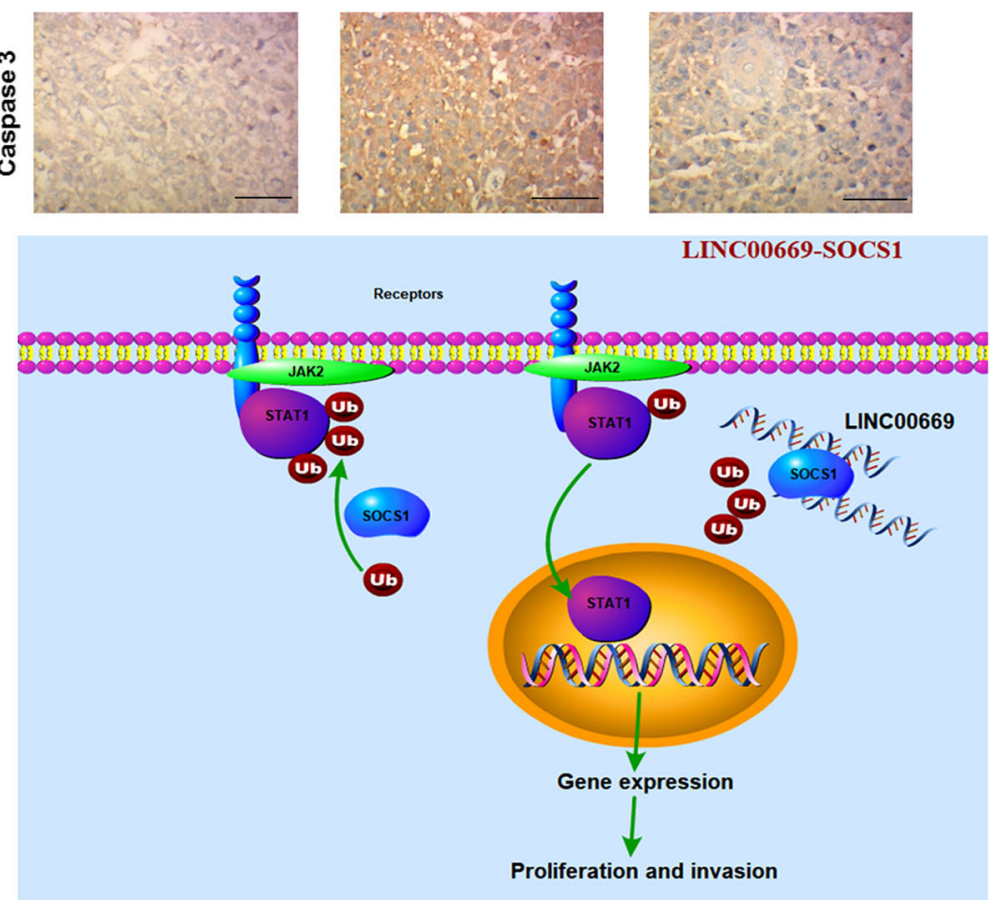

Fig. 8 SOCS1 is indispensable for tumor-promoting function of LINC00669 in vivo. a, Tumor growth curves as recorded by measuring tumor volume. Depletion of LINC00669 hampered xenograft tumor growth in nude mice, which could be partially rescued by simultaneous knockdown of SOCS1 in NPC cells. NC, negative control; siLINC, siRNA-mediated silencing of LINC00669; siSOCS1, siRNA-mediated silencing of SOCS1. b, Representative images showing xenograft tumors. c, IHC results showing the number of proliferating $\left(\mathrm{Ki}_{6} \mathrm{7}^{+}\right)$cells was decreased in tumors derived from LINC00669-depleted NPC cells, where the number of apoptotic (Caspase $3^{+}$) cells was increased accordingly. In contrast,

simultaneous knockdown of SOCS1 in the LINC00669-depleted NPC cells restored cell proliferation and suppressed apoptosis in the xenograft tumors. $\mathbf{d}$, The activation of JAKVSTAT signaling pathway is under tight control of SOCS1 in normal cells. The growth homeostasis is interrupted due to the aberrant expression of LINC00669. Mechanistically, abnormal accumulation of cytosolic LINC00669 competitively binds to SOCS1, and insulates it from touching the transcription factor STAT1 for ubiquitination modification, which stabilizes STAT1 and promotes further phosphorylation by escaping from the proteasomal degradation. The activated STAT1 then enters the nuclei and initiates the transcriptional program associated with cell proliferation and invasion

LINC00669 participates in regulating the JAK-STAT signaling pathway negative feedback loop of SOCS1/ STAT1, through which it plays an oncogenic role in NPC tumorigenicity.
The localization of lncRNAs within a cell is the primary determinant of their molecular functions. Cabili and colleagues used FISH to directly visualize the regional RNA expression and observed the complex localization patterns 
of 34 lncRNAs, which can be divided into five categories: large nuclear foci, large nuclear foci with single molecules scattered through the nucleus, predominantly nuclear without foci, cytoplasmic and nuclear, and predominantly cytoplasmic [24]. Generally, nuclear lncRNAs act as chromatin-restricted regulators of gene transcription and chromatin structure [25-28]. Instead, sufficient evidence shows that cytoplasmic localized lncRNAs perform parts suitable for the cytoplasm including translational regulation, signaling, and respiration. For example, IncRNAs interacting with microRNA are enriched in the cytoplasm $[29,30]$. In addition, lncRNAs that control protein stability or mRNA translation efficiency are also more common in the cytoplasm and ribosomes [31-33]. In agreement to these assumptions, LINC0069, which is cytoplasmically enriched in NPC cells, does not directly set up cancerous transcriptome, but to regulate the JAK/STAT signaling pathway through the physical binding to inactivate its key negative feedback regulator SOCS1 in the cytoplasm.

SOCS proteins are potent JAK/STAT signaling pathway suppressors. All SOCS family members are featured with a $\mathrm{SH} 2$ domain and a brief C-terminal domain, namely SOCS box1 that is physically associated with the adaptor complex, elonginBC2 [34, 35]. This connection facilitates the ubiquitination of signal intermediates by recruiting the E3 ubiquitin ligase scaffold (Cullin5) [18]. Except for the common ubiquitin ligase activity, SOCS1 and SOCS3 are capable of a direct inhibition on JAK kinase activity through a short motif called Kinase Inhibitory Region [18], which is however, unlikely true in NPC cells in that lacking of the direct interaction between SOCS1 and JAK. Instead, SOCS1 directs proteasomal degradation of STAT1 by catalyzing ubiquitination on the protein.

Constitutive activation of STAT1 and STAT3 has been reported in NPC tissues [36]. However, the abnormal STAT3 activity in NPC should not be ascribed to the aberrant expression of LINC00669 since it remained stable regardless of the changes in LINC00669 expression. Instead, STAT1 is highly responsive to the cytosolic content of LINC00669, whose ectopic expression leads to increases in both total and phosphorylated STAT1. Inhibition of STAT1 can enhance the radiosensitivity of CNE-2R cells, and knockout STAT1 causes cell growth retardation and apoptosis both in vitro and in vivo [37]. Therefore, we consider STAT1 as a key effector in LINC00669/SOCS1/JAK-STAT signaling cascade, which compiles cancerous transcriptome in NPC cells.

In conclusion, although it has been aware of the aberrant activation of the JAK/STAT signaling pathway in NPC tumors for long, its causes remain largely underexplored. We revealed in current study that IncRNA LINC00669 was upregulated in NPC cell cytoplasm, where it binds to SOCS1, and blocks its ubiquitination modification function toward STAT1. Interruption of such negative feedback machinery enhances STAT1 stability and facilitates its phosphorylation and thus nuclear translocation to initiate the proliferation and invasionassociated transcriptome. Our study not only provides a novel marker for diagnosis and prognosis of NPC, but also highlights it a potential target for therapy.

\section{Supplementary information}

Supplementary information accompanies this paper at https://doi.org/10. 1186/s13046-020-01674-z.

\section{Additional file 1}

\section{Abbreviations}

Co-IP: Co-immunoprecipitation; DAB: Diaminobenzidene; EBV: Epstein-Barr virus; FBS: Fetal bovine serum; FISH: Fluorescence in situ hybridization; HOTAIR: HOX transcript antisense intergenic RNA;

IHC: Immunohistochemistry; JAK: Janus kinase; IncRNA: Iong non-coding RNA; MEG3: Maternally expressed gene 3; NPC: Nasopharyngeal carcinoma; Nt: Nucleotides; qPCR: quantitative PCR; RIP: RNA immunoprecipitation; STAT: Signal transducer of activators of transcription

\section{Acknowledgements}

None.

\section{Authors' contributions}

Xiang Qing, Guo-lin Tan and Huo-wang Liu conceived and designed the study. Wei Li, Jin-gang Ai and Shan-shan Xiong performed experiments. Shan-shan Xiong collected the data. Meng-qing Yang and Shan-shan Xiong interpreted the data. Tian-sheng Wang and Xiang Qing analyzed the data and wrote the manuscript. All authors reviewed the results and approved the final version of the manuscript.

\section{Funding \\ None}

\section{Availability of data and materials}

The datasets generated/analyzed in the present study are available upon reasonable request from the corresponding author.

\section{Ethics approval and consent to participate}

This study was approved by the Ethics Committee of The Third Xiangya Hospital, and all patients involved provided written informed consent.

\section{Consent for publication}

Written informed consent for publication was obtained from all participants.

\section{Competing interests}

The authors declare that they have no conflict of interest.

\section{Author details}

${ }^{1}$ Department of Otolaryngology Head and Neck Surgery, The Third Xiangya Hospital, Central South University, Changsha 410013, China. ${ }^{2}$ Department of Postgraduate Office, Third Xiangya Hospital, Central South University,

Changsha 410013, China.

Received: 16 June 2020 Accepted: 11 August 2020

Published online: 24 August 2020

\section{References}

1. Chen YP, Chan ATC, Le QT, Blanchard P, Sun Y, Ma J. Nasopharyngeal carcinoma. Lancet. 2019;394:64-80.

2. Brennan B. Nasopharyngeal carcinoma. Orphanet J Rare Dis. 2006;1:23.

3. Nusslein HG, Spiegelberg HL. Interleukin-4 induces both lgG4 and lgE secretion by peripheral blood B cells. J Clin Lab Anal. 1990;4:414-9. 
4. Tao CJ, Liu X, Tang LL, Mao YP, Chen L, Li WF, Yu XL, Liu LZ, Zhang R, Lin $\mathrm{AH}, \mathrm{Ma}$ J, Sun Y. Prognostic scoring system for locoregional control among the patients with nasopharyngeal carcinoma treated by intensity-modulated radiotherapy. Chin J Cancer. 2013;32:494-501.

5. Guttman M, Amit I, Garber M, French C, Lin MF, Feldser D, Huarte M, Zuk O, Carey BW, Cassady JP, Cabili MN, Jaenisch R, Mikkelsen TS, Jacks T, Hacohen N, Bernstein BE, Kellis M, Regev A, Rinn JL, Lander ES. Chromatin signature reveals over a thousand highly conserved large non-coding RNAs in mammals. Nature. 2009:458:223-7.

6. Chak WP, Lung RW, Tong JH, Chan SY, Lun SW, Tsao SW, Lo KW, To KF. Downregulation of long non-coding RNA MEG3 in nasopharyngeal carcinoma. Mol Carcinog. 2017:56:1041-54.

7. Fu WM, Lu YF, Hu BG, Liang WC, Zhu X, Yang HD, Li G, Zhang JF. Long noncoding RNA Hotair mediated angiogenesis in nasopharyngeal carcinoma by direct and indirect signaling pathways. Oncotarget. 2016;7:4712-23.

8. Nie Y, Liu X, Qu S, Song E, Zou H, Gong C. Long non-coding RNA HOTAIR is an independent prognostic marker for nasopharyngeal carcinoma progression and survival. Cancer Sci. 2013;104:458-64.

9. Li XX, Liang XJ, Zhou LY, Liu RJ, Bi W, Zhang S, Li SS, Yang WH, Chen ZC, Yang XM, Zhang PF. Analysis of differential expressions of long non-coding RNAs in nasopharyngeal carcinoma using next-generation deep sequencing. J Cancer. 2018;9:1943-50.

10. O'Shea JJ, Schwartz DM, Villarino AV, Gadina M, McInnes IB, Laurence A. The JAK-STAT pathway: impact on human disease and therapeutic intervention. Annu Rev Med. 2015:66:311-28.

11. Croker BA, Kiu H, Nicholson SE. SOCS regulation of the JAK/STAT signalling pathway. Semin Cell Dev Biol. 2008;19:414-22.

12. Chen $H$, Lee JM, Wang $Y$, Huang DP, Ambinder RF, Hayward SD. The Epstein-Barr virus latency BamHI-Q promoter is positively regulated by STATs and Zta interference with JAK/STAT activation leads to loss of BamHIQ promoter activity. Proc Natl Acad Sci U S A. 1999;96:9339-44.

13. Jiang MC, Ni JJ, Cui WY, Wang BY, Zhuo W. Emerging roles of IncRNA in cancer and therapeutic opportunities. Am J Cancer Res. 2019;9:1354-66.

14. Hsu WL, Tse KP, Liang S, Chien YC, Su WH, Yu KJ, Cheng YJ, Tsang NM, Hsu MM, Chang KP, Chen IH, Chen TI, Yang CS, Goldstein AM, Chen CJ, Chang YS, Hildesheim A. Evaluation of human leukocyte antigen-a (HLA-A), other non-HLA markers on chromosome 6p21 and risk of nasopharyngeal carcinoma. PLoS One. 2012;7:e42767.

15. Bao YN, Cao X, Luo DH, Sun R, Peng LX, Wang L, Yan YP, Zheng LS, Xie $P$, Cao Y, Liang YY, Zheng FJ, Huang BJ, Xiang YQ, Lv X, Chen QY, Chen MY, Huang PY, Guo L, Mai HQ, Guo X, Zeng YX, Qian CN. Urokinase-type plasminogen activator receptor signaling is critical in nasopharyngeal carcinoma cell growth and metastasis. Cell Cycle. 2014;13:1958-69.

16. Agostini F, Zanzoni A, Klus P, Marchese D, Cirillo D, Tartaglia GG. catRAPID omics: a web server for large-scale prediction of protein-RNA interactions. Bioinformatics. 2013;29:2928-30.

17. Sharma J, Larkin J 3rd. Therapeutic implication of SOCS1 modulation in the treatment of autoimmunity and Cancer. Front Pharmacol. 2019;10:324.

18. Kamizono S, Hanada T, Yasukawa H, Minoguchi S, Kato R, Minoguchi M, Hattori K, Hatakeyama S, Yada M, Morita S, Kitamura T, Kato H, Nakayama K, Yoshimura A. The SOCS box of SOCS-1 accelerates ubiquitin-dependent proteolysis of TEL-JAK2. J Biol Chem. 2001;276:12530-8.

19. Yasukawa H, Misawa H, Sakamoto H, Masuhara M, Sasaki A, Wakioka T, Ohtsuka S, Imaizumi T, Matsuda T, Ihle JN, Yoshimura A. The JAK-binding protein JAB inhibits Janus tyrosine kinase activity through binding in the activation loop. EMBO J. 1999;18:1309-20.

20. Yang L, Shi P, Zhao G, XU J, Peng W, Zhang J, Zhang G, Wang X, Dong Z, Chen F, Cui H. Targeting cancer stem cell pathways for cancer therapy. Signal Transduct Target Ther. 2020;5:8.

21. Bousoik E, Montazeri AH. "Do we know Jack" about JAK? A Closer Look at JAK/STAT Signaling Pathway. Front Oncol. 2018;8:287.

22. Rawlings JS, Rosler KM, Harrison DA. The JAK/STAT signaling pathway. J Cell Sci. 2004;117:1281-3

23. Aaronson DS, Horvath CM. A road map for those who don't know JAKSTAT. Science. 2002;296:1653-5.

24. Cabili MN, Dunagin MC, McClanahan PD, Biaesch A, Padovan-Merhar O, Regev A, Rinn JL, Raj A. Localization and abundance analysis of human IncRNAs at single-cell and single-molecule resolution. Genome Biol. 2015;16:20.

25. Kirsch E. So-called isolated genital tuberculosis in man. A contribution to the etiology, diagnosis, therapy and prognosis. Z Tuberk Erkr Thoraxorg. 1964;121:257-67.
26. Hacisuleyman E, Goff LA, Trapnell C, Williams A, Henao-Mejia J, Sun L, McClanahan P, Hendrickson DG, Sauvageau M, Kelley DR, Morse M, Engreitz J, Lander ES, Guttman M, Lodish HF, Flavell R, Raj A, Rinn JL. Topological organization of multichromosomal regions by the long intergenic noncoding RNA firre. Nat Struct Mol Biol. 2014;21:198-206.

27. Mondal T, Subhash S, Vaid R, Enroth S, Uday S, Reinius B, Mitra S, Mohammed A, James AR, Hoberg E, Moustakas A, Gyllensten U, Jones SJ, Gustafsson CM, Sims AH, Westerlund F, Gorab E, Kanduri C. MEG3 long noncoding RNA regulates the TGF-beta pathway genes through formation of RNA-DNA triplex structures. Nat Commun. 2015;6:7743.

28. Clemson CM, Hutchinson JN, Sara SA, Ensminger AW, Fox AH, Chess A, Lawrence JB. An architectural role for a nuclear noncoding RNA: NEAT1 RNA is essential for the structure of paraspeckles. Mol Cell. 2009;33:717-26.

29. Cesana M, Cacchiarelli D, Legnini I, Santini T, Sthandier O, Chinappi M, Tramontano A, Bozzoni I. A long noncoding RNA controls muscle differentiation by functioning as a competing endogenous RNA. Cell. 2011; 147:358-69.

30. Shukla CJ, McCorkindale AL, Gerhardinger C, Korthauer KD, Cabili MN, Shechner DM, Irizarry RA, Maass PG, Rinn JL. High-throughput identification of RNA nuclear enrichment sequences. EMBO J. 2018;37:e98452.

31. Cai R, Sun Y, Qimuge N, Wang G, Wang Y, Chu G, Yu T, Yang G, Pang W. Adiponectin AS IncRNA inhibits adipogenesis by transferring from nucleus to cytoplasm and attenuating Adiponectin mRNA translation. Biochim Biophys Acta Mol Cell Biol Lipids. 2018;1863:420-32.

32. Carrieri C, Cimatti L, Biagioli M, Beugnet A, Zucchelli S, Fedele S, Pesce E, Ferrer I, Collavin L, Santoro C, Forrest AR, Carninci P, Biffo S, Stupka E, Gustincich S. Long non-coding antisense RNA controls Uchl1 translation through an embedded SINEB2 repeat. Nature. 2012;491:454-7.

33. Yoon JH, Abdelmohsen K, Srikantan S, Yang X, Martindale JL, De S, Huarte M, Zhan M, Becker KG, Gorospe M. LincRNA-p21 suppresses target mRNA translation. Mol Cell. 2012;47:648-55.

34. Hilton DJ, Richardson RT, Alexander WS, Viney EM, Willson TA, Sprigg NS, Starr R, Nicholson SE, Metcalf D, Nicola NA. Twenty proteins containing a C-terminal SOCS box form five structural classes. Proc Natl Acad Sci U S A. 1998;95:114-9.

35. Babon JJ, Sabo JK, Soetopo A, Yao S, Bailey MF, Zhang JG, Nicola NA, Norton RS. The SOCS box domain of SOCS3: structure and interaction with the elonginBC-cullin5 ubiquitin ligase. J Mol Biol. 2008;381:928-40.

36. Chen $\mathrm{H}$, Lee JM, Zong Y, Borowitz M, Ng MH, Ambinder RF, Hayward SD. Linkage between STAT regulation and Epstein-Barr virus gene expression in tumors. J Virol. 2001;75:2929-37.

37. Qu S, Guo Y, Huang ST, Zhu XD. Inhibition of STAT1 sensitizes radioresistant nasopharyngeal carcinoma cell line CNE-2R to radiotherapy. Oncotarget. 2018:9:8303-10.

\section{Publisher's Note}

Springer Nature remains neutral with regard to jurisdictional claims in published maps and institutional affiliations.

Ready to submit your research? Choose BMC and benefit from:

- fast, convenient online submission

- thorough peer review by experienced researchers in your field

- rapid publication on acceptance

- support for research data, including large and complex data types

- gold Open Access which fosters wider collaboration and increased citations

- maximum visibility for your research: over $100 \mathrm{M}$ website views per year

At $\mathrm{BMC}$, research is always in progress.

Learn more biomedcentral.com/submissions 